\title{
Age and sex interactions in mountain ultramarathon running - the Swiss Alpine Marathon
}

This article was published in the following Dove Press journal:

Open Access Journal of Sports Medicine

30 July 2012

Number of times this article has been viewed

\author{
Evelyn Eichenberger' \\ Beat Knechtle ${ }^{1,2}$ \\ Christoph Alexander Rüst' \\ Thomas Rosemann' \\ Romuald Lepers ${ }^{3}$ \\ 'Institute of General Practice and \\ Health Services Research, University \\ of Zurich, Zurich, Switzerland; \\ ${ }^{2}$ Gesundheitszentrum St Gallen, St \\ Gallen, Switzerland; '3NSERM UI093, \\ Faculty of Sport Sciences, University \\ of Burgundy, Dijon, France
}

Background: The aims of the study were to examine the (a) participation, (b) difference in running times between the sexes, and (c) age-related decline in the running times of ultramarathoner women and men competing in the Swiss Alpine Marathon from 1998 to 2011.

Methods: The ultramarathoners competing in the Swiss Alpine Marathon were analyzed in terms of participation, difference in running times between the sexes, age of the fastest runners, and age-related decline in the fastest running times. The race covers a distance of $78 \mathrm{~km}$, with a total altitude change of approximately $2260 \mathrm{~m}$. A total of 12,194 men and 1781 women finished the race between 1998 and 2011.

Results: Women's participation increased from approximately $10 \%$ in 1998 to approximately $16 \%$ in $2011\left(\mathrm{r}^{2}=0.57 ; P=0.001\right)$, but participation remained unchanged in men $\left(\mathrm{r}^{2}=0.17\right.$; $P>0.05)$. Over the years, the top ten women showed no change in running times $\left(\mathrm{r}^{2}=0.02\right.$; $P>0.05)$, whereas the top ten men's running times increased $\left(\mathrm{r}^{2}=0.46 ; P<0.01\right)$. The age for peak running times increased over time both for the top ten women $\left(\mathrm{r}^{2}=0.58 ; P<0.01\right)$ and for the top ten men $\left(r^{2}=0.40 ; P=0.01\right)$.

Conclusion: Among the top women, participation increased, the age for peak running times increased, and the running times remained unchanged. Among the men, however, the participation remained steady, and both the peak running-time age and the running times increased.

Keywords: ultra-endurance, aging, sex difference, running

\section{Introduction}

Participation in marathon and ultramarathon running events - ultramarathons are extralong distance running events, longer than the traditional marathon distance of $42.195 \mathrm{~km}$ - has increased tremendously since the $1980 \mathrm{~s} .{ }^{1-6}$ Participation in $161 \mathrm{~km}$ ultramarathons in the USA increased in the early to mid-1980s, but has remained stable since $1986 .^{2,3}$ In 1998, in North America, only twenty-one $161 \mathrm{~km}$ ultramarathon events were held, but the number of events increased to 53 per year in $2008 .^{1}$ This growth reflected an increased interest in ultra-endurance running by the participating athletes. ${ }^{2}$

An individual's performance in ultra-endurance running can be affected by different factors. ${ }^{7}$ It has been shown that age $\mathrm{e}^{5,8}$ and $\operatorname{sex}^{8-10}$ can influence performance. As to sex, women's performance progressed considerably over recent decades. ${ }^{11}$ Despite women not being able to close the sex gap in marathon running, some authors suggested that the sex difference would disappear for running distances greater than that of a marathon. ${ }^{12,13}$ For instance, Hoffman showed there was no difference in $80 \mathrm{~km}$ and $161 \mathrm{~km}$ running performances between women and men who had matching $50 \mathrm{~km}$ running times. ${ }^{14}$ In contrast, Coast et al analyzed the fastest running times of women
Correspondence: Beat Knechtle Facharzt FMH für Allgemeinmedizin, Gesundheitszentrum St Gallen, Vadianstrasse 26, 9001 St Gallen, Switzerland Tel +4I 7I 2268282 Fax +4I 712268272

Email beat.knechtle@hispeed.ch 
and men for distances ranging from $100 \mathrm{~m}$ to $200 \mathrm{~km}$ and showed that men's running speed was $12.4 \%$ faster than women's. Moreover, as the distance increased, so did the gap between the sexes. ${ }^{15}$ Cheuvront et al reported a difference between the sexes of $8 \%-14 \%$ for running distances from $1500 \mathrm{~m}$ to $42 \mathrm{~km} .{ }^{16}$ In contrast, Speechly et al reported that women who were matched with men for a $42.2 \mathrm{~km}$ run were faster than men in a $90 \mathrm{~km}$ race. ${ }^{13}$ The women achieved their performances by running at a higher average fraction of maximum oxygen uptake ( $\left.\mathrm{VO}_{2} \max \right)$.

The difference in running performance between men and women might be explained by differences in anthropometry and physiology. Men have a higher skeletal muscle mass than women do, which could cause the difference. ${ }^{17}$ Men, having larger hearts, also have a higher stroke volume and therefore a higher cardiac output. ${ }^{17}$ The vascularization of the skeletal muscle mass is lower in women, due to their lower blood volume. These two factors combined result in a lower oxygen capacity for women. Also, $\mathrm{VO}_{2} \max$ is $15 \%$ to $25 \%$ lower in female athletes than in males. ${ }^{17}$

Several studies investigated the age-related decline in endurance and ultra-endurance performance..$^{5,18-20}$ For example, an analysis of male and female $100 \mathrm{~km}$ ultramarathoners showed that the fastest runners were 30 - to 40-year-old men and 30- to 54-year-old women. ${ }^{5}$ Similarly, Hoffman reported that the fastest average running time in a $161 \mathrm{~km}$ ultramarathon was achieved by athletes aged between 35 and $40 .{ }^{3}$ Reaburn and Dascombe noted that maintaining both high-intensity and high-volume training could mitigate the age-related decrease in running performance. ${ }^{21}$ However, beyond age 55 years, running performance decreased in both sexes, most pronouncedly in women..$^{21,22}$

To date, no study has investigated the participation and running times of ultramarathoner women and men competing in high alpine terrain. The Swiss Alpine Marathon is one of the premier mountain ultramarathons in Europe (http://www.swissalpine.ch). The race covers a distance of $78 \mathrm{~km}$ and has a total altitude change of approximately $2260 \mathrm{~m}$. The hilly trail and huge altitude change comprise an enormous challenge for the runners. The question arises whether younger athletes handle the hilly terrain better than older ones, since with increasing age, body fat increases and skeletal muscle mass decreases. ${ }^{21}$ Indeed, it might be possible that, in a mountain ultramarathon such as the Swiss Alpine Marathon, the age-related decline would be greater if compared to traditional ultramarathons. Regarding differences between the sexes, when climbing at high altitudes, women's lower body mass might give them an advantage over men. ${ }^{17}$ In contrast, their lower skeletal muscle mass might put them at a disadvantage. ${ }^{17}$

The aims of the study were to examine the (a) participation, (b) difference in running times between the sexes, and (c) age-related decline in running times in ultramarathoner women and men competing in the Swiss Alpine Marathon from 1998 to 2011. We hypothesized that (a) participation would increase in both sexes across the years, (b) the difference between the sexes in achieving peak running times in mountain ultramarathons would be greater, compared to reports on nonalpine ultra-endurance running, and (c) the age-related decline in peak running times would be greater in mountain ultramarathoners, compared to reported results from nonalpine ultramarathoners.

\section{Materials and methods}

This study was approved by the institutional review board of Kanton St Gallen, Switzerland, with a waiver of the requirement for informed consent, given that the study involved the analysis of publicly available data. The total race time, sex, and age of all the finishers of the Swiss Alpine Marathon from 1998 to 2011 were analyzed. The data set from this study was obtained from the race's website (http://www.swissalpine.ch).

\section{The race}

The Swiss Alpine Marathon was started by Andrea Tuffli in 1986. At that time, Switzerland already had a mountain running race, but not on similar terrain and not over a marathon distance. In 1986, the first race took place, albeit over a shorter distance than that of a true marathon. The race takes place annually in July in Davos, Switzerland. It is also called $\mathrm{K} 78$, because it covers a distance of $78 \mathrm{~km}$ and has a total altitude change of approximately $2260 \mathrm{~m}$. Figure 1 shows the course of the race over asphalt, natural trail, and high alpine trail. A $21 \mathrm{~km}$ section crosses a high alpine area whose highest altitude is approximately $2632 \mathrm{~m}$. The athletes start in Davos at $1538 \mathrm{~m}$ above sea level and descend to Filisur, the lowest point in the race, at $1019 \mathrm{~m}$ above sea level. Next, the runners climb to the highest point, the Keschhütte, at $2632 \mathrm{~m}$ above sea level, and then turn around and return to Davos. Over the race's entire distance, there are 31 aid stations offering food, and liquids such as water and hypotonic sports drinks. In addition, 17 paramedic stations are spread over the entire route. At the end of the field of runners, one runner is on duty showing the slowest runners the last possible time to reach the finish line. Between 1998 and 2011, no major changes in the distance or course of the race occurred. 


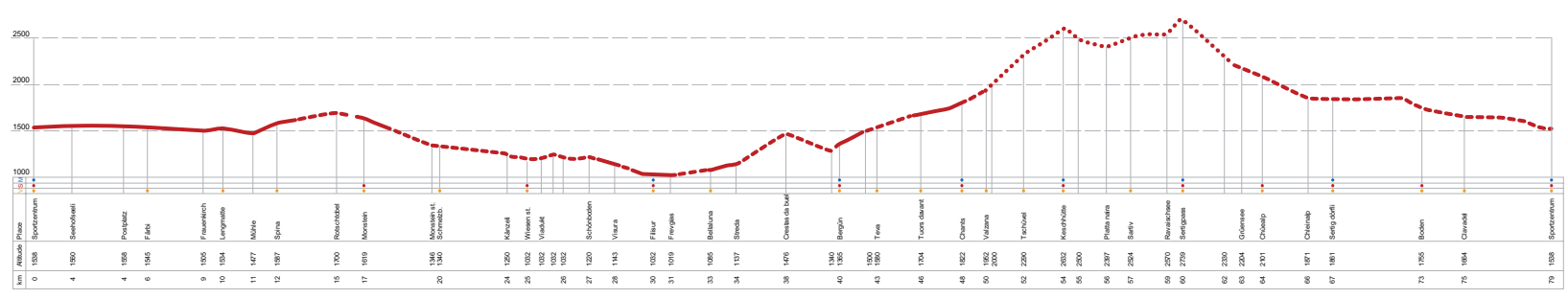

Figure I Profile of the Swiss Alpine Marathon course over asphalt (full line), natural trail (broken line), and high alpine trail (dotted line).

\section{Data analysis}

Data were available from 13,975 athletes. The running times and ages of the annual winners, the annual top ten finishers, and the overall finishers were assessed separately for women and men. Women and men were also separately evaluated for peak running-time age, annual winners, and annual top ten finishers. The difference between the sexes was calculated as ([men's running times] - [women's running times] $) \div$ [running times] $\times 100$ ).

\section{Statistical analysis}

Data in the text are given as mean \pm standard deviation (SD). Each set of data was tested for normal distribution and homogeneity of variances prior to statistical analyses. Normal distribution was tested using a D'Agostino and Pearson omnibus normality test. The homogeneity of variances was tested using a Levene's test in cases of two groups and a Bartlett's test in cases of more than two groups. To test significant changes in the development of a variable across years, linear regression was used. To find differences between two groups, a student's $t$-test was used in cases of normal distribution and a Mann-Whitney test in cases of data not distributed normally. A one-way analysis of variance (ANOVA) with subsequent Tukey-Kramer post hoc analysis was used to find differences between more than two groups. Statistical analyses were performed using IBM SPSS Statistics (Version 19; SPSS, Chicago, IL) and GraphPad Prism (Version 5; GraphPad Software, La Jolla, CA). Significance was accepted at $P<0.05$ (two-sided for $t$-tests).

\section{Results}

From 1998 to 2011, 12,198 men and 1781 women finished the Swiss Alpine Marathon. Women represented approximately $12 \%$ of the total field per year. On average, $127 \pm 47$ women and $871 \pm 134$ men finished the race each year (ranges: 83-251 women, 738-1233 men).

\section{Participation}

Women's participation increased from approximately $10 \%$ in 1998 to approximately $16 \%$ in $2011\left(\mathrm{r}^{2}=0.57 ; P=0.001\right)$.
Neither the number of men finishers nor the number of total finishers showed any changes over the years (Figure 2). The highest number of finishers was among the 40- to 44-year-old women and men (Figure 3).

\section{Differences between the sexes in running times}

Men were faster than women. The mean race time for all finishers was $607.9 \pm 23.7$ minutes for women and $582.7 \pm 19$ minutes for men $(P<0.001)$. The difference in overall running times between the sexes was 4.3 minutes $\pm 1.5 \%$. For the top runners, the running times remained unchanged over the years (Figure 4A). The annual mean running times were $354.9 \pm 8.1$ minutes for male winners $(P>0.05)$ and $412.6 \pm 12.2$ minutes for female winners $(P>0.05)$, with a difference between the sexes of 16 minutes $\pm 4 \%(P>0.05)$. For the top ten runners, women's running times remained unchanged at $460.4 \pm 13.4$ minutes $(P>0.05)$, whereas men's running times increased from $372 \pm 12$ minutes in 1998 to $410 \pm 19$ minutes in 2011 $\left(\mathrm{r}^{2}=0.46 ; P<0.01\right)$ (Figure 4B). The difference in running times between the sexes in the top ten decreased from $22 \%$ in 1998 to $17 \%$ in $2011\left(\mathrm{r}^{2}=0.29 ; P<0.05\right)$. Regarding overall running times, both women and men became significantly slower over the years (Figure 4C). The women's running times became slower as they aged. The running times increased from $606 \pm 82$ minutes in 1998 to $674 \pm 90$ minutes in 2011 $\left(\mathrm{r}^{2}=0.39 ; P=0.017\right)$. The men's running times increased from $568 \pm 83$ minutes in 1998 to $636 \pm 90$ minutes in 2011 $\left(\mathrm{r}^{2}=0.53 ; P=0.03\right)$. The difference in running times between the sexes remained unchanged at $6.7 \%(P>0.05)$.

\section{Peak running-time age and age-related decline in running times}

For the top runners, the mean age when peak running times were achieved was unchanged at $34.4 \pm 2.5$ years for women $(P>0.05)$ and unchanged at $33.9 \pm 4.2$ years for men $(P>0.05)$ (Figure 5A). The difference between the sexes 


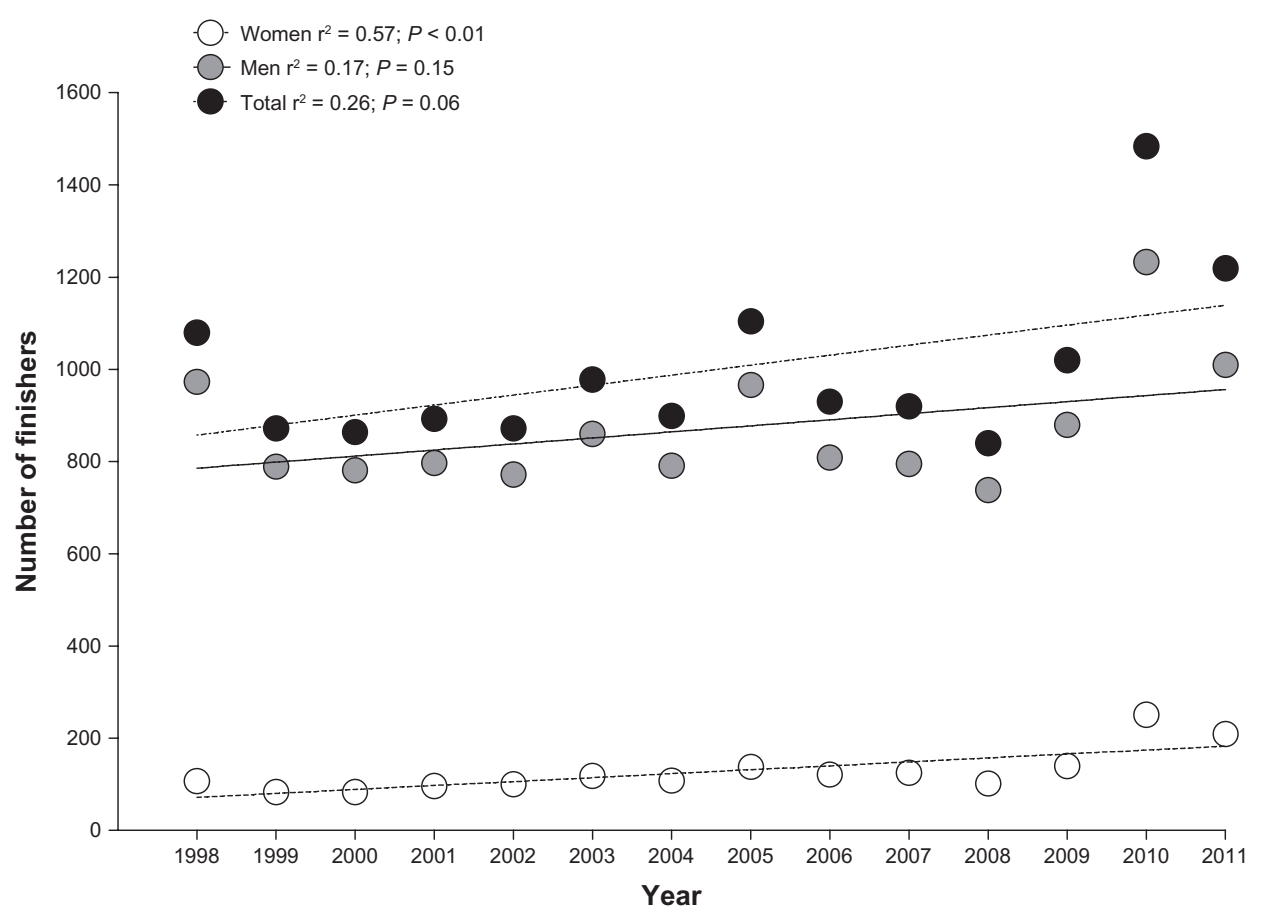

Figure 2 The number of men, women and total finishers in the Swiss Alpine Marathon, from 1998 to 201 I.

in peak running-time age decreased from $28.3 \%$ in 1998 to $5.4 \%$ in $2011\left(r^{2}=0.30 ; P<0.05\right)$. For the top ten runners, the peak running-time age increased across the years for both women and men (Figure 5B). For men, the peak runningtime age increased from $34 \pm 5$ years in 1998 to $38 \pm 5$ years in $2011\left(r^{2}=0.40 ; P=0.01\right)$. For women, it increased from
$32 \pm 5$ years to $39 \pm 6$ years $\left(\mathrm{r}^{2}=0.58 ; P<0.01\right)$. The difference between the sexes in age, however, remained unchanged, at 6 years $\pm 4.3 \%\left(r^{2}=0.12 ; P>0.05\right)$. The men's age-related decline in achieving peak running times started at age 55 and older (Figure 6). The women's decline started at age 45 and older. The fastest female athletes were

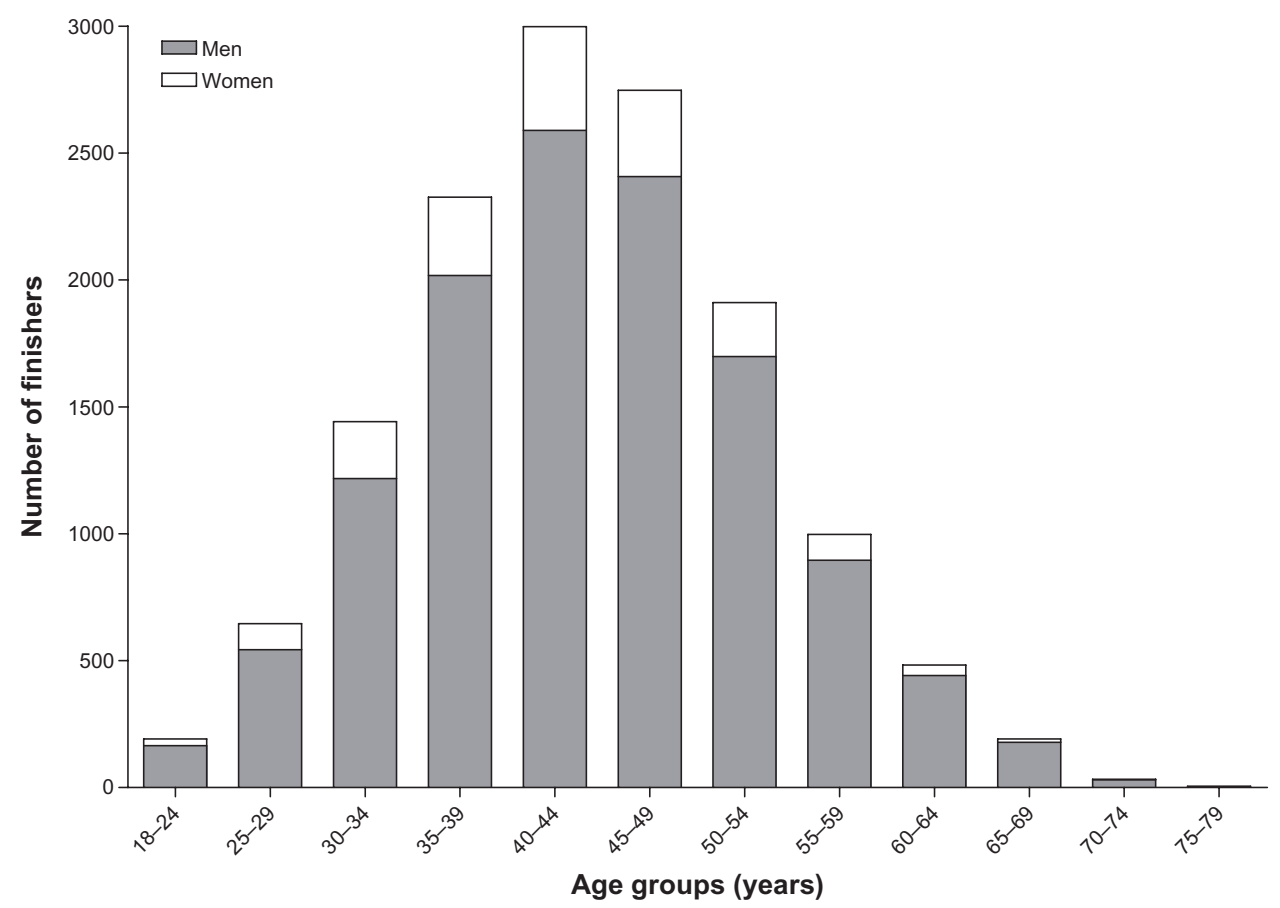

Figure 3 The total number of finishers by age group at the Swiss Alpine Marathon. 

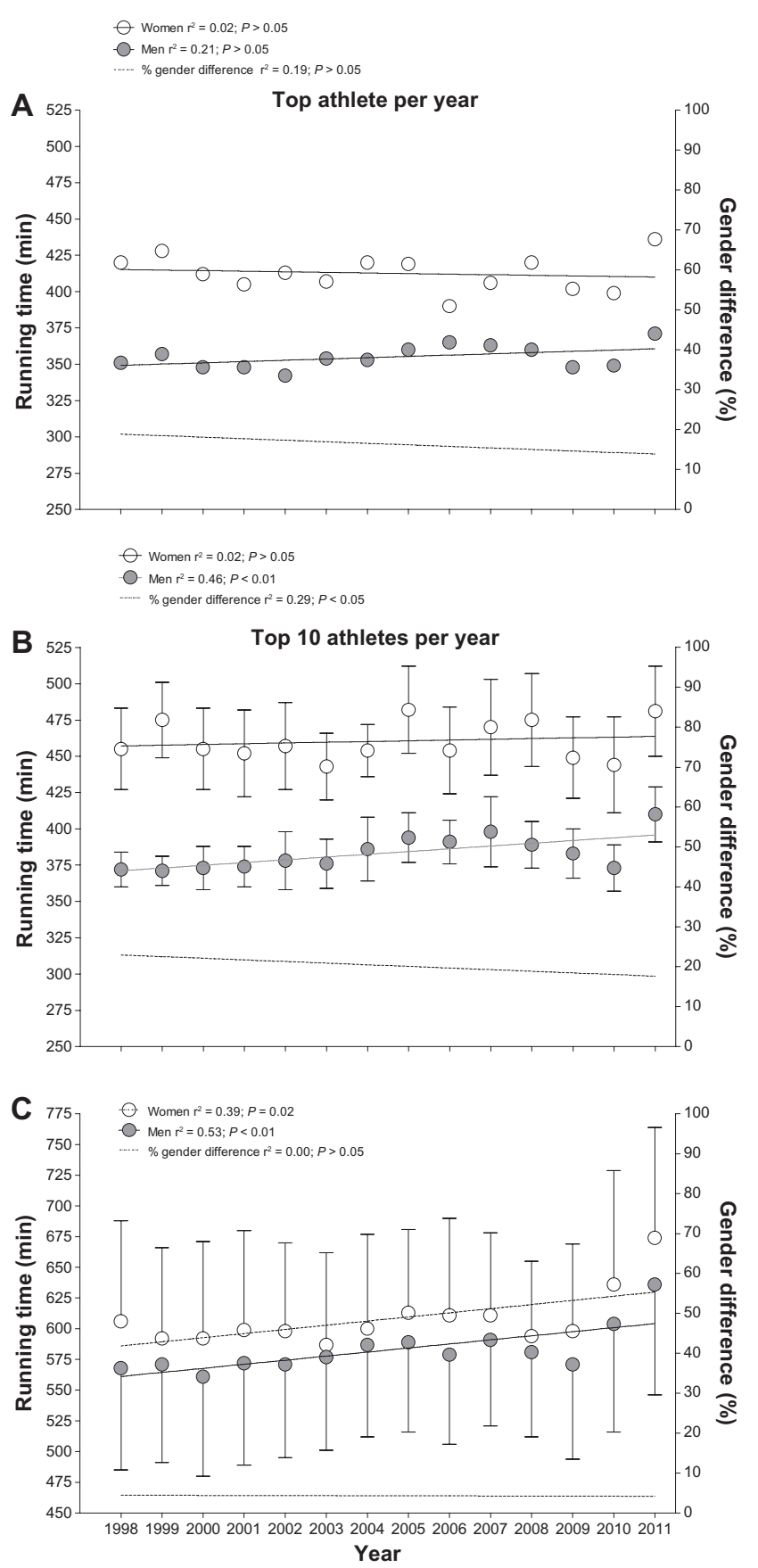

Figure 4 The changes in Swiss Alpine Marathon running times of the men and women winners $(\mathbf{A})$, the top ten men and women finishers $(\mathbf{B})$, and the overall men and women finishers (C), from 1998 to 2011 .

30-34 years old, with a mean race time of $404 \pm 9$ minutes; the fastest male athletes were 40-44 years old, with a mean race time of $344 \pm 43$ minutes.

\section{Discussion}

This study examined ultramarathoner women's and men's in terms of their participation, differences between the sexes in running times, and age-related declines in running times from 1998 to 2011 in the Swiss Alpine Marathon. It was hypothesized that participation would increase in both sexes over the years, that the difference between the sexes in achieving peak running times would be greater than that reported for nonalpine ultrarunning, and that the age-related decline in peak running times would be greater in mountain ultramarathoners than in nonalpine ultramarathoners.

\section{Participation}

A main finding regarding participation trends was that participation by women increased over the years, whereas men's participation remained unchanged. Men may have been looking for other challenges, such as sports requiring more technical abilities. ${ }^{9}$ Another explanation is that an enormous increase in men's participation in mountain ultramarathons had already occurred, as has been reported for $161 \mathrm{~km}$ ultramarathoners, ${ }^{2,3}$ but that by 1998 or so, the number of men participating had stabilized. This idea coincides with Hoffman's finding that the increase in the total number of finishers became stable in the $161 \mathrm{~km}$ ultramarathons. ${ }^{14}$

However, the number of women participating in ultraendurance running races increased. ${ }^{14}$ One reason might be that women started to participate in ultra-endurance races later than men did. ${ }^{3}$ Women seem to have increased their participation, as men had earlier. Another possible explanation is motivation. Krouse et al investigated the motivation of women ultramarathoners. ${ }^{23}$ For women, they found that both a general health orientation and psychological coping were the two strongest motivational factors for competing in an ultramarathon. Women showed a higher task orientation than ego orientation. Female ultrarunners were task-oriented subjects who were internally motivated, healthy, and financially conscious individuals. ${ }^{23}$

\section{Difference in running times between the sexes}

Men were faster than women; the difference in running times between the sexes was approximately $16 \%$ for the winners and approximately $20 \%$ for the top ten runners over the years. These differences between the sexes are larger than the values reported by Coast et al, in which men's running speeds when running 100-200 km were $12.4 \%$ faster than women's. ${ }^{15}$ Similarly, Cheuvront et al reported a difference between the sexes of $8 \%-14 \%$ faster for men running 1500-42,000 m. ${ }^{16}$ The larger gap between sexes in present-day mountain ultramarathoners could be due to the difference in skeletal muscle mass between women and men. ${ }^{17}$ Women's lower skeletal muscle mass might impair 

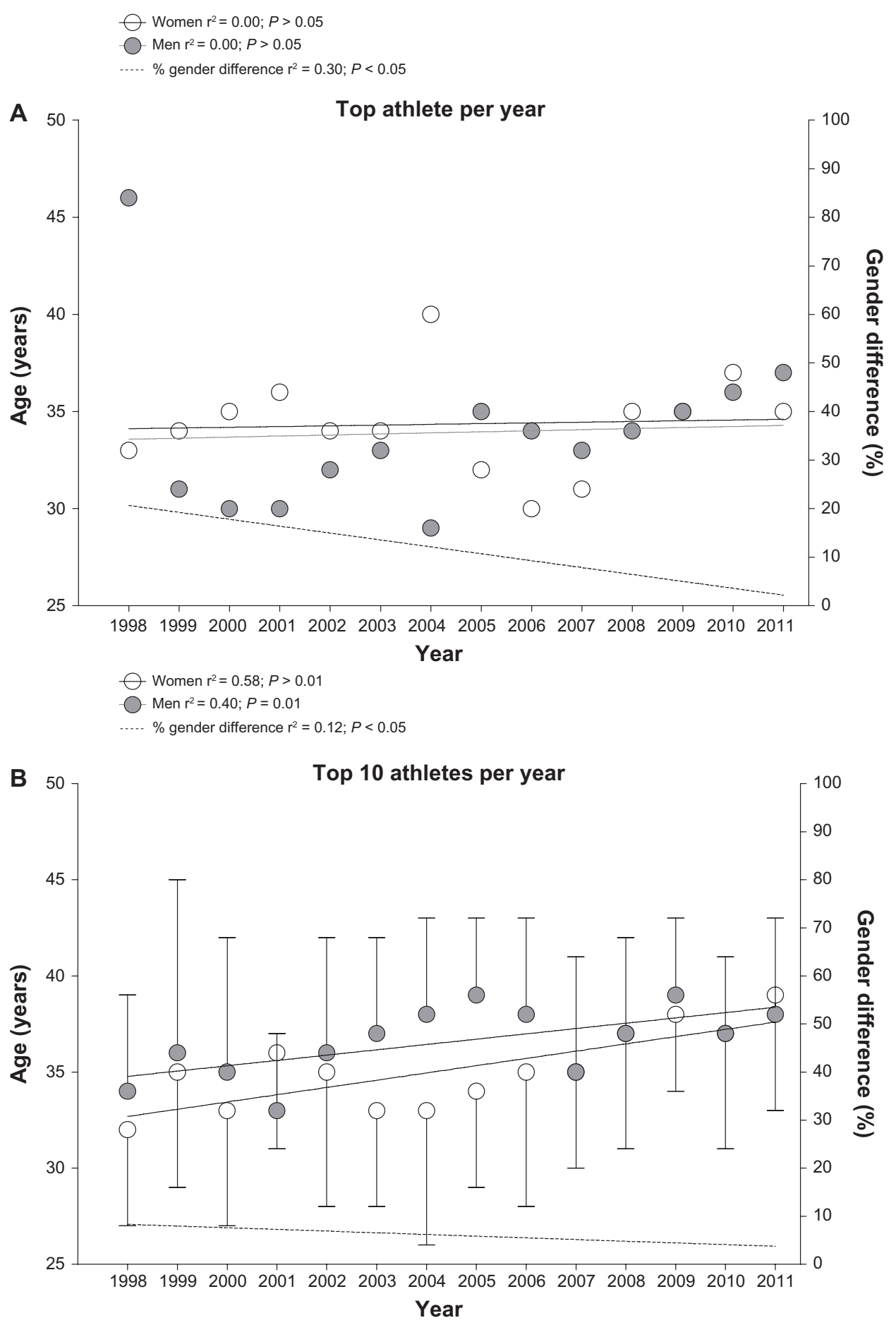

Figure 5 The development of the age of the men and women winners (A) and the top ten men and women finishers (B), from I998 to $201 \mathrm{I}$.

their ultra-endurance performance. Another interesting finding is that, among mountain ultramarathoners, men became significantly slower over the years, whereas women showed stable running times. The same findings were made by Knechtle et al in their study of the $100 \mathrm{~km}$ Lauf Biel event, from 1998 to 2010: the running times of the top ten men significantly increased, whereas the running times of the top ten women remained stable. ${ }^{5}$ One explanation could be that the number of competitive male athletes decreased over the period studied and that the number of recreational runners increased, as has been reported for $100 \mathrm{~km}$ ultramarathoners and Ironman triathletes. ${ }^{5,19,20}$ Also, over the years, the number of master runners might have increased at a higher rate among men than among women. 


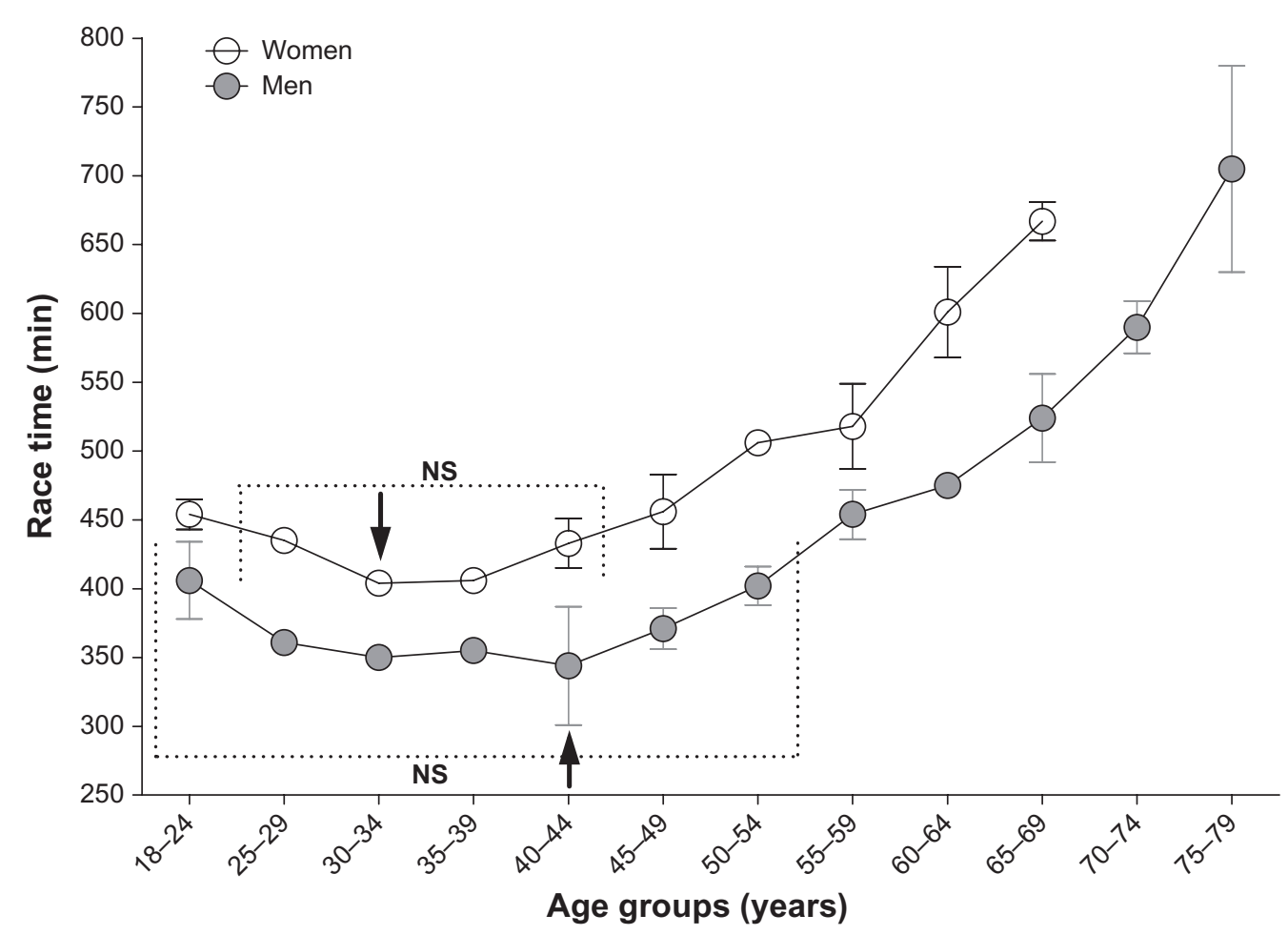

Figure 6 The age-related change in running times at the Swiss Alpine Marathon, from 1998 to 2011.

Note: The arrow indicates the fastest age group for both women and men.

Abbreviation: NS, no significant difference between the age groups.

\section{Peak running-time age and age-related decline in running times}

The peak running-time age increased over the years for both women and men. This finding might be explained by the findings of Burtscher et al, who reported on the top finishers of the World Masters Athletic Championships in Mountain Running in 2007: analyzed according to the finishers' membership in five-year age-range groups, race times did not significantly differ among those aged 35 to 49. ${ }^{24} \mathrm{VO}_{2}$ max was maintained at top levels in mountain runners of both sexes up to age 45-49. Among the present-day mountain ultramarathoners studied here, the decline in age-related running times starts after age 44 for women and after age 54 for men. Interestingly, in the $100 \mathrm{~km}$ Lauf Biel, the age-related decline running times started after age 54 for women and after age 49 for men. ${ }^{5}$ A possible reason for this apparent reversal is that the route of the Swiss Alpine Marathon is very hilly and at a high altitude, compared to the $100 \mathrm{~km}$ Lauf Biel. Also, the distance in the Swiss Alpine Marathon is shorter than in the $100 \mathrm{~km}$ Lauf Biel. Nevertheless, after age 55, the running times decreased in both sexes in the $100 \mathrm{~km}$ Lauf Biel, most pronouncedly in women. This coincides with the present study, where the decline in running times started in both sexes after age 55, and where the decline was more pronounced in women than in men. An explanation for the women's higher decline in running times could be that female athletes have a lower skeletal muscle mass than do male athletes. ${ }^{17,25}$ In addition, skeletal muscle mass decreases with increasing age,${ }^{26}$ which may also lead to impaired running times.

\section{Conclusion}

The top female mountain ultramarathoners' participation in the race and peak running-time age increased over the years, but their peak running times remained unchanged. In contrast, the top male mountain ultramarathoners' participation did not change, and their peak running-time age and running times increased. Future studies need to investigate what motivates men ultramarathoners. Also, the change in the participation of male master runners in different age groups needs further investigation.

\section{Acknowledgment}

The authors thank Mary Miller for her help in translation.

\section{Disclosure}

The authors report no conflicts of interest in this work. 


\section{References}

1. Hoffman MD, Fogard K. Factors related to successful completion of a 161-km ultramarathon. Int J Sports Physiol Perform. 2011;6:25-37.

2. Hoffman MD, Ong JC, Wang G. Historical analysis of participation in $161 \mathrm{~km}$ ultramarathons in North America. Int J Hist Sport. 2010;27: 1877-1891.

3. Hoffman MD, Wegelin JA. The Western States 100-Mile Endurance Run: participation and performance trends. Med Sci Sports Exerc. 2009; 41:2191-2198.

4. Lepers R, Cattagni, T. Do older athletes reach limits in their performance during marathon running? Age (Dordr). 2012;34:773-781.

5. Knechtle B, Rüst CA, Rosemann T, Lepers R. Age-related changes in 100-km ultra-marathon running performance. Age (Dordr). July 28, 2011. DOI: 10.1007/s11357-011-9290-9.

6. Hoffman MD. Performance trends in 161-km ultramarathons. Int J Sports Med. 2010;31:31-37.

7. Miranda-Vilela AL, Akimoto AK, Lordelo GS, Pereira LC, Grisolia CK, Klautau-Guimarães Mde N. Creatine kinase MM TaqI and methylenetetrahydrofolate reductase $\mathrm{C} 677 \mathrm{~T}$ and A1298C gene polymorphisms influence exercise-induced C-reactive protein levels. Eur J Appl Physiol. 2012;112:941-950.

8. Knechtle B, Knechtle P, Rosemann T, Lepers R. Predictor variables for a $100-\mathrm{km}$ race time in male ultra-marathoners. Percept Mot Skills. 2010;111:681-693.

9. Baker AB, Tang YQ. Aging performance for masters records in athletics, swimming, rowing, cycling, triathlon, and weightlifting. Exp Aging Res. 2010;36:453-477.

10. Leyk D, Erley O, Ridder D, et al. Age-related changes in marathon and half-marathon performances. Int J Sports Med. 2007;28:513-517.

11. Pate RR, O'Neill JR. American women in the marathon. Sports Med. 2007;37:294-298.

12. Bam J, Noakes TD, Juritz J, Dennis SC. Could women outrun men in ultramarathon races? Med Sci Sports Exerc. 1997;29:244-247.

13. Speechly DP, Taylor SR, Rogers GG. Differences in ultraendurance exercise in performance-matched male and female runners. Med Sci Sports Exerc. 1996;28:359-365.

14. Hoffman MD. Ultramarathon trail running comparison of performancematched men and women. Med Sci Sports Exerc. 2008;40: 1681-1686.
15. Coast JR, Blevins JS, Wilson BA. Do gender differences in running performance disappear with distance? Can J Appl Physiol. 2004;29: 139-145.

16. Cheuvront SN, Carter R, DeRuisseau KC, Moffatt RJ. Running performance differences between men and women: an update. Sports Med. 2005;35:1017-1024.

17. Lynch SL, Hoch AZ. The female runner: gender specifics. Clin Sports Med. 2010;29:477-498.

18. Lepers R, Maffiuletti, N. Age and gender interactions in ultraendurance performance: insight from triathlon. Med Sci Sports Exerc. 2011;43: 134-139.

19. Stiefel M, Knechtle B, Lepers R. Master triathletes have not reached limits in their Ironman triathlon performance. Scand J Med Sci Sports. May 14, 2012. DOI: 10.1111/j.1600-0838.2012.01473.x.

20. Lepers R, Rüst CA, Stapley PJ, Knechtle B. Relative improvements in endurance performance with age: evidence from 25 years of Hawaii Ironman racing. Age (Dordr). February 28, 2012. DOI: 10.1007/s11357012-9392-z.

21. Reaburn P, Dascombe B. Endurance performance in masters athletes. Eur Rev Aging Phys Act. 2008;5:31-42.

22. Easthope CS, Hausswirth C, Louis J, Lepers R, Vercruyssen F, Brisswalter J. Effects of a trail running competition on muscular performance and efficiency in well-trained young and master athletes. Eur J Appl Physiol. 2010;110:1107-1116.

23. Krouse RZ, Ransdell LB, Lucas SM, Pritchard ME. Motivation, goal orientation, coaching, and training habits of women ultrarunners. J Strength Cond Res. 2011;25:2835-2842.

24. Burtscher M, Förster H, Burtscher J. Superior endurance performance in aging mountain runners. Gerontology. 2008;54:268-271.

25. Knechtle B, Wirth A, Baumann B, Knechtle P, Rosemann T, Oliver S. Differential correlations between anthropometry, training volume, and performance in male and female Ironman triathletes. J Strength Cond Res. 2010;24:2785-2793.

26. Shephard RJ. Age and physical work capacity. Exp Aging Res. 1999;25: 331-343.
Open Access Journal of Sports Medicine

\section{Publish your work in this journal}

Open Access Journal of Sports Medicine is an international, peer-reviewed, open access journal publishing original research, reports, reviews and commentaries on all areas of sports medicine. The manuscript management system is completely online and includes a very quick and fair peer-review system.

\section{Dovepress}

Visit http://www.dovepress.com/testimonials.php to read real quotes from published authors. 